\title{
Reading and the Training School Library
}

Mildred Hawksworth Lowell is research assistant to the dean, Graduate Library School, University of Chicago.

$\mathrm{O}$ THE PROBLEMS characteristic of a training school library about which a teachers college librarian might speak, that of reading seems most pertinent and appropriate at this time for two reasons.

First, because the state of the world at present and the national defense theme of this conference point to a more active participation by librarians in the study of the influence of reading on public opinion. People in democracies need to read with intelligence and discrimination in order to detect propaganda, to arrive at considered judgments, and to achieve a tolerant equilibrium. Librarians aid in formulating the attitudes and opinions of readers through the selection and distribution of printed materials. Particularly is this true of school and college librarians who guide the reading of the younger generation at the time when many of their ideas and prejudices are being formed. It is true that librarians try to fit the "right book to the right child" and to provide the college student with suitable printed materials on his immediate problems. But, in selecting and distributing these materials are such factors as the following considered?-the reading ability of the reader; the reading experience or background of the reader which will condition how he interprets the printed material; and the effects on the reader of what he has read.

\section{The Library the Scene of Action}

Second, because the new education, as found in most teachers colleges, is making new demands upon the library staff and is making reading basic to all the activities of the school. Curricular emphasis has shifted from textbook-learning to a learning which involves the whole personality of the individual-physiological, physical, emotional, mental, and social. This new type of teaching and learning situation is an active education concerned with relating the educational program of each boy and girl to his or her individual differences and capabilities. Pupils search through printed materials for that information which will help them solve particular problems. The library rather than the classroom is frequently the scene of action and the librarian rather than the teacher is the guide to the materials of instruction. Such a situation makes demands upon the librarian which necessitates a broad and sufficient knowledge of all areas of reading.

Perhaps a cursory inspection of the various factors involved in reading may help training school librarians as well as other librarians to visualize more effectively their role in democracy and in education. 


\section{The Larger Conception of Reading}

In the past ten years, the conception of reading has broadened from a subject limited to the elementary grades taught by a few teachers to a subject extending from the kindergarten through and beyond college and taught by all teachers of every subject at all levels. Reading is no longer considered an isolated skill or an end in itself; it is now regarded as one part of the broad complicated pattern of communication. Reading has expanded from a narrow concern with mechanics to include the social and emotional aspects of reading.

The old narrow conception conceived of reading as the process of recognizing printed or written symbols. This involved accuracy in recognizing words and phrases, rhythmical progress of perceptions along lines, comprehension, and speed. The concept today is far more comprehensive as it also includes a clear grasp of the meaning implied, an accurate understanding of the facts and ideas presented, and an integration of the ideas into definite thought and action patterns. The reader's apprehension of meaning involves his background of related experiences, his enlargement of previous concepts, and his acquisition of new experiences. Inherent in this broader definition of reading is the concept that reading is a form of experience which modifies personality, deepens understanding, stimulates intellectual and emotional growth, and alters behavior.

Facts about reading do not fit any one academic discipline but overlap several fields. Education, psychology, librarianship, sociology, publishing, political science, journalism, and literature all contribute to the knowledge of reading. Scholars and students working in the different areas of reading are inclined to think of reading in their own field and to neglect studies of reading in other fields. Psychologists are apt to think of reading in terms of nerve responses; physiologists in terms of physical aspects of the eye and ear; educators in terms of how to teach reading; librarians in terms of "who reads what;" and sociologists in terms of the propaganda effects of reading. Each of these areas is essential to an understanding of reading. One might think of reading as a crystal with many faces, each face of which presents a different aspect or area.

The field of reading might be divided into the following four major divisions: (I) the physiological aspects of the reading process, (2) the social uses and effects of reading, (3) the content analysis of publications, and (4) the methodology of reading instruction.

The Physiological Aspects of the Reading Process

This is logically of first consideration since an individual must have the necessary physical equipment before he is able to read. In this field, the following types of information contribute to the reading act: the individual's visual, vocal, and mental processes; his breathing apparatus; his bodily movements; and hygienic conditions of the body conducive to reading. Reading studies in this field include eyemovements, fixation pauses, regressions, span of recognition, perception, or recognition of words, apprehension of meanings and pronunciations, reading readiness or degree of maturity of the individual, and amount of light necessary for effective and comfortable vision.

Knowledge of these aspects of reading are useful to librarians in several ways. First, such information directly affects the planning of library buildings. Provision 
should be made for keeping the reader's body in a good reading position, for tables of proper height and shape, for enough foot-candles of light at every place where reading will be engaged in, and for quiet congenial surroundings. Second, such information makes librarians aware of the disabilities or the difficulties which readers may be experiencing. Being aware of the difficulties makes for much more understanding and helpful service on the part of the library staff. In the third place, such information helps in building a book collection suitable for the mental and physical abilities of the young people in the school or college. For example, because ophthalmologists are agreed that the eye reaches maturity by the time the child is eight or nine years of age or earlier, it has been found that young children read fairly small type more easily than they do large type. ${ }^{1}$ This means that librarians need no longer search for books written in large type for kindergarten and firstgrade children.

\section{The Social Uses and Effects of Reading}

If an individual has the necessary physiological equipment for reading, reading as a social process is the next logical consideration. This includes: the cultural, social, and physical conditions affecting publishing activity; the distribution and availability of reading materials; the traits and motivations of readers; the reaction to and use of the ideas apprehended; and the effects of reading on the individual and on the group. The social uses of reading need to be studied in relation to other social agencies and influences.

1 National Society for the Study of Education. 36th Yearbook, Pt. I: "Teaching of Reading: $a$ Second Report." Public School Publishing Company, Bloomington, Ill., 1937, p. $231-32$.
It has only been within the last decade that systematic and scientific programs of research in the sociology of reading have been undertaken. A recent book ${ }^{2}$ reviews the pertinent literature in this field and brings together what is known about the subject by advertisers, publishers, authors, teachers, librarians, and publicity agents. The writers of this book point out that clarity in discussing the effects of reading demands attention to the following five major factors: ${ }^{3}$

(I) the social context (folkways and group conflicts and personal conditions), which explains the publication of some writings and non-publication of others; (2) the methods of distributing publications, which explain the variations between what different groups of people would prefer to read and what they do read; (3) the differences among the publications themselves, which explain why and how some are more influential than others; and (4) the different predispositions of readers, which explain why the same publication will incite one reader to revolutionary action, will be vigorously condemned by another, and will be ignored or read with apathy by a third. To these, for logical completeness, should be added a fifth; namely, (5) the influence of other communications than reading, since the influences of radio, films, public speeches, or private conversations may either reinforce or offset the influences of reading as such.

Reading studies of this type clarify the pressing problem of analyzing public opinion. Since schools and libraries should be interested in controlling the influences of reading in the public interest, educators and librarians should seek to apply these factors to their practical working situations in order to facilitate such control. Librarians could encourage desirable read-

\footnotetext{
${ }^{2}$ Waples, Douglas; Berelson, Bernard; and Bradshaw, Franklyn R. What Reading Does to People: a Summary of Evidence on the Social Effects of Reading and a Statement of Problems for Research. The University of Chicago Press, 1940.
} 
ing by proper control of book selection, of distribution, and of other factors which can be controlled.

\section{Content Analysis of Publications}

The reading content of publications is responsible for many of the differences between the social effects of reading and the social effects of other communications and other experiences. Content analysis seeks to describe publications with primary attention to their influences upon typical readers. There are several ways of analyzing content. For example, advertisers and propagandists analyze in terms of the effectiveness of publications in exploiting the consumer and the citizen. Social scientists analyze publications to describe changes in social attitudes or indications of social conflicts and processes. This field is just developing and can be expected to contribute substantially to the sociology of reading in the near future.

"Basic English" or the semantic approach is one form of content analysis which has achieved considerable notice recently. It investigates multiple meanings, generalizations or abstractions, and the relations between thought and feelings in language. It attempts to bring words closer to experience and experience closer to words. It recognizes that communication and thinking are inseparable. The persons who have probably done the most in this field are: C. K. Ogden, ${ }^{4}$ I. A. Richards, ${ }^{5}$ and Alfred Korzybski. ${ }^{6}$ Stuart Chase attempted to popularize the idea of semantics in his Tyranny of Words. ${ }^{7}$

'Ogden, C. K., and Richards, I. A. The Meaning of Meaning; 5 th ed. Kegan Paul, Trubner \& Co., Ltd., 1938 .

Harcourt

orcourt, 1938. A. Interpretations in Teaching. Introduction to Non-Aristotelian Systems and General Semantics; 2d ed. The Science Press, I940. eral Semantics; ${ }^{2 d}$ ed. The Science Press, 940.
Chase, Stuart. The Tyranny of Words. Har. court, 1938 .
Count Korzybski has an Institute of General Semantics in Chicago which is attracting students from all parts of the country.

\section{Methodology of Reading Instruction}

This division of reading is placed last because it is based on the preceding three. Reading cannot be taught intelligently unless the teacher has a thorough comprehension of each of the above phases of the reading problem. Each of the factors which have been isolated and determined in the other three areas of reading must be related to the teaching situation. As research in all areas of reading progresses, the conceptions of the nature and character of reading change. These new factors and changes inevitably influence the role of reading in education. This latter area includes organization of the reading curriculum; determination of grade placement and time allotment for specific reading activities; selection and study of reading materials and vocabulary ; development of basic habits and skills, method of teaching, and tests and measurements; and remediation and diagnosis of reading problems and disabilities.

In the past, reading instruction has been limited to the lower elementary grades. But because of the widespread criticism of the inability of college students to read, there are indications that in the years just ahead reading instruction will be part of the instructional program of all schools from first grade through college. The type of instruction for the upper levels will be radically different from that taught in the lower grades; and might include the characteristics of inductive and deductive thinking, the techniques of critical interpretation and evaluation, and the elements of logic and scientific method.

Mortimer J. Adler's currently popular 
How to Read a $B o o k^{8}$ is pertinent to this phase of reading. Dr. Adler points out that reading extends all the way up to the bachelor's degree; and that the techniques of communication are the first obligation of a sound educational program in a democracy which depends upon a literate electorate. $^{\ominus}$

\section{Conclusion}

In view of the changed conception of reading in recent years, of recent research which reveals the importance of the effects of reading, and of the extension of reading instruction up through college, is it not logical to ask what active part the school and college librarian is to play in the future?

This enlarged concept of reading requires a broader and more extensive

Adler, Mortimer J. How to Read a Book, the Art of Getting a Liberal Education. 'Simon and Schuster, I 940.

Ibid., pp. 80-81. knowledge of books than individual teachers ordinarily possess; and it requires a greater knowledge of reading than librarians ordinarily possess. At present in most schools and colleges reading is everyone's and no one's business. Because of the increasing importance of all four of the reading areas herein outlined, it would seem that schools and colleges may find it necessary to have some one person as a director of reading or director of uses of print. Should this person be teacher or librarian? Either would have to know much more about all aspects of reading than most do at present. In addition, the teacher would have to know more about books. Since librarians already possess knowledge of books, they might be the logical persons to direct the uses of print if they are willing to prepare themselves in the physiological, sociological, analytical, and educational areas of reading. 